\title{
Is the risk of Delirium reduced in Minimal Invasive Cardiac Surgery
}

\author{
Chaud Germán J ${ }^{1 *}$, Simon M Belén², Filippa Pablo A ${ }^{1}$, Gavotti G Carolina ${ }^{2}$, Ferreyra Lilian², Flores Marcela $^{2}$, \\ Paladini Guillermo ${ }^{1}$ and Martinez Colombres M Alejandro ${ }^{1}$ \\ ${ }^{1}$ Department of Cardiac Surgery, Hospital Privado Universitario de Córdoba, Instituto Universitario de Ciencias Biomédicas de Córdoba, Argentina \\ ${ }^{2}$ Department of Psychiatric, Hospital Privado Universitario de Córdoba, Instituto Universitario de Ciencias Biomédicas de Córdoba, Argentina
} Submission: May 07, 2019; Published: June 19, 2019

*Corresponding author: Germán J Chaud, Hospital Privado Centro Médico de Córdoba, Naciones Unidas 346, (5016) Córdoba, Argentina

\begin{abstract}
Background: The number of cardiac operations is steadily increasing in industrialized countries, being Delirium one of the most frequent postoperative complications. Aortic Valve Replacement by mini-invasive surgery has reported to offer innumerable benefits over Complete Sternotomy, such as better esthetic, less surgical trauma, pain, blood and postoperative complications, a functional recovery and a shorter hospital stay.

Objectives: To determine the frequency of Delirium and to identify its risk factors in patients undergoing mini-sternotomy (MS) versus full sternotomy (FS) isolated aortic valve replacement (AVR).

Methods: An interdisciplinary, descriptive and retrospective study of 113 adults patients who underwent an Isolated Aortic Valve Replacement (AVR) with mini-sternotomy (MS) and full sternotomy (FS) was conducted. Variables related to delirium were characterized as being present before, during or after cardiac surgery.

Results: Delirium occurred in 26 patients (23\%). In the MS group, 12 patients (25\%) had Delirium while 36 (75\%) had no Delirium. In the FS group, 14 (21.5\%) patients had Delirium whereas 51 did not have it (78.5\%) and P: 0.66. Regarding to valve type among Delirium patients, 5 had a mechanical one while 21 patients with a biological valve. P: 0.02. Late extubation had 7 (6.2\%) patients in the Delirium group versus 1 (9\%) in the non-Delirium group. P: 0.001. Postoperative $\mathrm{Hb}$ analysis revealed an average of $9.2 \mathrm{mg} / \mathrm{dL}$ and $9.8 \mathrm{mg} / \mathrm{dl}$ for Delirium and non - Delirum patients respectively. P: 0.05 . Renal disease was showed in 8 (7.1\%) patients in the Delirium group versus 4 in the No delirium group ( $3.5 \%)$ with a P value of 0.001 . No mortality event has been registered in any of the groups.
\end{abstract}

Conclusion: MS has shown numerous advantages over conventional surgery before this study, nevertheless the risk of Delirium has not been previously assessed in this context. The risk factors and an increasing frequency of Delirium should be taking into account due to its high morbidity rate and significant cost of the health system.

Keywords: Delirium; Confutional syndrome; Cardiac surgery; Aortic valve replacement; Minimally invasive cardiac surgery; Full sternotomy

Abbreviations: AVR: Aortic Valve Replacement; CEC: Extracorporeal Circulation; Clamp: Clamping time; COPD: Chronic Obstructive Pulmonary Disease; FS: Full-Sternotomy; MS: Mini-Sternotomy; EVD: Peripheral Vascular Disease; RI: Renal Insufficiency; MICS: Minimall Invasive Cardiac Surgery; TAVI: Transcatheter Aortic Valve Implantation

\section{Introduction}

The rapid aging of the population has led to the appearance of a new type of surgical patient different from the traditional one, with the coexistence of different chronic diseases, numerous drugs and less functional reserve. That situation makes it more susceptible in stress situations to develop perioperative complications such as Delirium or Confusional Syndrome [1].

Besides, the number of cardiac operations is steadily increasing in industrialized countries, being Delirium one of the most frequent postoperative complications with an incidence varying from $3 \%$ to $52 \%$. Postoperative delirium is usually transient and can be resolved spontaneously, but in some cases it is associated with a large number of serious complications such as cognitive and functional impairment, prolonged hospital stay and an increased mortality and morbidity. The cause of post-cardiac surgery delirium is unknown and is probably multifactorial in origin. Valve Counting Procedures such as Aortic Valve Replacement as well as those combined with extracorporeal 


\section{Journal of Cardiology \& Cardiovascular Therapy}

circulation have demonstrated higher rates of Delirium compared to non-cardiopulmonary bypass. In addition, other independent predictors have been strongly related to Delirium, such as advanced age, history of Cerebrovascular Disease (OR 2.15), Diabetes (OR 1.30), peripheral vascular disease (OR 1.34), atrial fibrillation (OR 1.35), alcohol use(OR 6.11), low ejection fraction (OR 1.30), high requirement for blood transfusions (OR 3.12), prolonged intubation time (OR 1.20), and prolonged stay in intensive care units (OR 1.11) [2-5]. Gottesman and colleagues showed that delirium following cardiac surgery is an independent predictor of death after 10 years postoperatively [6].

Regarding to the surgical technique, Aortic Valve Replacement by mini-invasive surgery has reported to offer innumerable benefits over Complete Sternotomy, such as better esthetic, less surgical trauma, pain, blood and postoperative complications, a functional recovery and a shorter hospital stay [7-9].

The possibility that Postoperative Delirium may be modifiable makes it an attractive target to identify its risk factors, and with that, improve the quality of care in cardiac surgical patients.

This study represents the first investigation ever made comparing specifically Delirium on different approach techniques.

\section{Methods}

An interdisciplinary, descriptive and retrospective study

Table 1: Preoperative demographic variables.

\begin{tabular}{|c|c|c|c|}
\hline Variables & FS & MS \\
\hline Gender & $36-55.4 \%(\mathrm{M}) 29-44.6 \%(\mathrm{~F})$ & $31-64.6 \%(\mathrm{M}) 17-35.4 \%(\mathrm{~F})$ & 0,32 \\
\hline Age (years) & $<69-.36(50 \%) \geq 70-36(50 \%)$ & $<69-.33(61.1 \%) \geq 70-21(38.9 \%)$ & 0,2 \\
\hline Psyquiatric Disease & $19(16.8 \%)$ & $7(6.2 \%)$ & 0.06 \\
\hline Reduced Ejection Fraction $(<50 \%)$ & $6(9.2 \%)$ & $8(16.7 \%)$ & 0,23 \\
\hline Atrial fibrillation & $13(20 \%)$ & $7(6.2 \%)$ & 0,46 \\
\hline COPD & $16(24.6)$ & $5(14.6 \%)$ & 0,2 \\
\hline Renal Insufficiency & $7(10.8 \%)$ & $15(13.3 \%)$ & $0,9 \%$ \\
\hline Diabetes & $16(14.2 \%)$ & $18(15.9 \%)$ & 0.4 \\
\hline Psyquiatric Medication & $27(23.9 \%)$ & $9(8 \%)$ & 0,27 \\
\hline Smoking & $18(15.9 \%)$ & $33(68.8 \%)$ &, 013 \\
\hline Hypertension & $57(87.7 \%)$ & $7(14.6 \%)$ & 0,24 \\
\hline History of Stroke & $5(7.7 \%)$ & $9(8.8 \%)$ &, 078 \\
\hline Vascular disease & $5(7.7 \%)$ & & 0.4 \\
\hline
\end{tabular}

Table 2: Analysis of Delirium in preoperative variables.

\begin{tabular}{|c|c|c|c|}
\hline Variables & No Delirium & Delirium \\
\hline Gender (M/F) & $50-74.6 \%(\mathrm{M}) 37-80.4 \%(\mathrm{~F})$ & $17-25.4 \%(\mathrm{M}) 9-19.6 \%(\mathrm{~F})$ & 0,47 \\
\hline Age (years) & 64.4 & 72,6 & 0,001 \\
\hline Psyquiatric Disease & $17(15 \%)$ & $9(8 \%)$ & 0.1 \\
\hline Reduced Ejection Fraction $(<50 \%)$ & $9(64.3 \%)$ & $5(35.7 \%)$ & 0,23 \\
\hline Atrial fibrillation & $14(70 \%)$ & $6(30 \%)$ & 0,4 \\
\hline COPD & $17(73.9 \%)$ & $6(26.1 \%)$ & 0,7 \\
\hline Renal Insufficiency & $6(50 \%)$ & $6(50 \%)$ & 0,02 \\
\hline
\end{tabular}

of adults patients admitted to perform an Isolated Aortic Valve Replacement (AVR) at Hospital Privado Universitario de Córdoba in the period from January 1, 2011 to December 31, 2015 was

An interdisciplinary, descriptive and retrospective study was conducted. The inclusion criteria included adults between 25 and 85 years of age who underwent an Isolated Aortic Valve Replacement (AVR) with mini-sternotomy or full sternotomy (FS).The selection of the type of surgery depended of the surgeon's preference were excluded all patients with Aortic Valve Replacement combined with Coronary surgery, Mitral Valve or Ascending aorta replacement, pediatric patients, those who died within 48 hours of surgery prior to being extubated and patients with story of Infective Endocarditic, prolonged hospital stay procedure was developed.

The data were extracted from the electronic medical record recorded in tables characterizing the variables as being present before, during or after cardiac surgery, and analyzed using the statistical software IBM ${ }^{\circ}$ SPSS Statics Version 19. To compare categorical variables was utilized Chi2 test or fisher's exact test as appropriate. A P value less than 0.05 was considered statistically significant. Continuous variables with a normal distribution were compared with T-test and for those with non-Gaussian distribution variables the Mann-Whitney U-test was used (Tables 1-3). 
Journal of Cardiology \& Cardiovascular Therapy

\begin{tabular}{|c|c|c|c|}
\hline Diabetes & $24(77.4 \%)$ & $7(22.6 \%)$ & 0,9 \\
\hline Psyquiatric Medication & $30(26.5 \%)$ & $15(13.3 \%)$ & 0.03 \\
\hline Smoking & $21(77.8 \%)$ & $6(22.2 \%)$ & 0,9 \\
\hline Hypertension & $68(75.6 \%)$ & $22(24.4 \%)$ & 0,4 \\
\hline History of Stroke & $8(66.7 \%)$ & $4(33.3 \%)$ & 0,37 \\
\hline Vascular disease & $9(64.3 \%)$ & $5(35.7 \%)$ & 0,23 \\
\hline
\end{tabular}

Table 3: Intraoperative Variables according to surgical technique.

\begin{tabular}{|c|c|c|c|}
\hline & FS & MICS & P \\
\hline Type of intervention & 65 & 48 & --- \\
\hline CPB (minutes) & 94.93 & 104.8 & 0.7 \\
\hline $\begin{array}{c}\text { Cross clamp time } \\
\text { (minutes) }\end{array}$ & 75.68 & 81.35 & 0.42 \\
\hline Re intervention & $3(75 \%)$ & $1(25 \%)$ & 0.47 \\
\hline Type of valve & $\begin{array}{c}\text { Mechanical 26 } \\
(60.5 \%) \\
\text { Biological 39 } \\
(55.7 \%)\end{array}$ & $\begin{array}{c}\text { Mechanical 17 } \\
(39.5 \%) \\
\text { Biological 31 } \\
(44.3 \%)\end{array}$ & 0.6 \\
\hline
\end{tabular}

Table 4: Intraoperative variables according to Delirium or No Delirium.

\begin{tabular}{|c|c|c|c|}
\hline Variables & No delirium & Delirium & $\mathbf{P}$ \\
\hline CPB (minutes) & 100.31 & 95.15 & 0.13 \\
\hline Cross clamp time (minutes) & 79.86 & 72.15 & 0.13 \\
\hline Re-Intervention & 2 & 2 & 0.19 \\
\hline Mechanical valve & 38 & 5 & \multirow{2}{*}{0.02} \\
\hline Biological Valve & 49 & 21 & \\
\hline FS & $51(78.5 \%)$ & $14(21.5 \%)$ & \multirow{2}{*}{0.66} \\
\hline MICS & $36(75 \%)$ & $12(25 \%)$ & \\
\hline
\end{tabular}

Table 5: Demographic postoperative variables according to type of intervention.

\begin{tabular}{|c|c|c|c|}
\hline & FS & MS & P \\
\hline Late extubation & $5(4.4 \%)$ & $3(2.7 \%)$ & 0.76 \\
\hline Fever & $15(13.3 \%)$ & $18(15,9 \%)$ & 0.96 \\
\hline Atrial fibrilation & $17(15 \%)$ & $13(11.5 \%)$ & 0.91 \\
\hline Acute renal insuficiency & $7(6.2 \%)$ & $5(4,4 \%)$ & 0,95 \\
\hline Post-op hemoglobin (g/dL) & 9.5 & 9.9 & 0.07 \\
\hline $\begin{array}{c}\text { Duration of Hospitalization stay } \\
\text { (days) }\end{array}$ & 7.9 & 7 & 0.33 \\
\hline $\begin{array}{c}\text { Duration of coronary unit stay } \\
\text { (days) }\end{array}$ & 3.86 & 3.77 & 0.66 \\
\hline Onset of Delirim (day) & 1.9 & 1.8 & 0.3 \\
\hline Complications & $24(21.2 \%)$ & $25(22.1 \%)$ & 0.1 \\
\hline
\end{tabular}

Table 6: Postoperative variables according to Delirium or No Delirium.

\begin{tabular}{|c|c|c|c|}
\hline & No delirium & Delirium & P \\
\hline Late extubation & $1(9 \%)$ & $7(6.2 \%)$ & 0.001 \\
\hline Post-op hemoglobin (g/dL) & 9,8 & 9,2 & 0,05 \\
\hline Fever & $24(21,2 \%)$ & $9(8 \%)$ & 0,49 \\
\hline Atrial Fibrilation & $19(16.8 \%)$ & $11(9.7 \%)$ & 0,03 \\
\hline Acute renal insufficiency & $4(3.5 \%)$ & $8(7.1 \%)$ & 0.00 \\
\hline
\end{tabular}

A search in different databases (pubmed, science direct, Scopus) was performed with the following key words or mesh terms: Delirium, minimally invasive, cardiac surgery, aortic valve replacement, Adults in order to identify previous work related to Delirium and minimally invasive cardiac surgery (Tables 4-6).

\section{Surgery Data}

In all patients, central cannulation for extracorporeal circulation was performed. Myocardial protection consisted of antegrade and retrograde administration of blood cardioplegia. Standard techniques were used to remove the native aortic valve, decalcify the aortic ring and insert the new prosthesis. The same technique of L-ministernotomies was also used up to the 4 intercostal space in all patients.

Variables were select using universal definitions and according to Society of Thoracic Surgery National Database specifications:

- Delirium is an acute confusional state with a fluctuating course, characterized by a disturbance in attention and awareness. This is accompanied by a change in memory, disorientation, alteration in language, or perceptual distortion or a perceptualmotor disturbance [10].

- Late extubation is defined as the cessation of assisted mechanical ventilation after the first 8 postoperative hours.

History of Psyquiatric Disease such as Mood Disorder, Cognitive Impairment Psychotic disorder previous psychiatric medication as anxiolytics, anti dementials, antidepressants and antipsychotics). History of consumption of toxic substances consisted in the use and abuse of licit and illicit drugs as cocaine, marijuana and alcohol. Reintervention was described as the performance of a new surgical procedure after the main surgery during the same hospitalization. Conversion was defined as the development of a full-sternotomy during the same procedure in which mini-sternotomy was previously performed. These were analyzed in the CD group. Complication was defined as the diagnosis of pneumonia, pleural effusion, tracheobronchitis, surgical site infection, urinary infection and pericarditis made after the procedure.

All identified Delirium cases were retrospectively reviewed by professionals from the Psychiatry Service.

\section{Results}

The analysis included 126 patients, 13 of whom were excluded due to: 9 for Infective Endocarditis, 1 patient older than 85 years old, 1 younger than 25 years of age, 1 presented prolonged 
hospitalization with delirium prior to surgery and 1 died in the immediate postoperative period before extubation.

The final sample consisted in 113 patients, 67 of who were male and 46 females. The mean age was $66 \pm 11$ (ą SD) with a range of 25-83 years separated in 2 groups according to their age in over 70 or under 69 years old. Regarding to the number of surgeries, 48 MS (42.5\%) and 65 FS (57.5\%) were performed. Of the total ME, only 2 required FS conversion and the same were analyzed in the FS group. Delirium occurred in 26 patients (23\%). In the MS group, 12 patients (25\%) had Delirium while 36 (75\%) had no Delirium. In the FS group, 14 (21.5\%) patients had Delirium whereas 51 did not have it (78.5\%) and P: 0.66.

The data were analyzed and grouped in preoperative demographic variables, in which no statistically significant differences were found.

We analyzed the same variables separated in 2 groups Delirium and No Delirium. It showed a significant difference in age in which mean of 64.4 years for No delirium Vs 72.6 years for the Delirium group (P: 0.001) were obtained. The variables history of Renal Insufficiency and Psychiatric medication showed significant values.

The intraoperative variables analysis showed that, of the 26 patients with Delirium, 5 had a mechanical valve and 21 had biological valve with a significant P. P 0.02. Re-intervention was evidenced in 2 patients of each group. P: 0.47. CPB duration had a mean of 95.15 minutes for patients with Delirium Vs 100.31 minutes for those without it. P: 0.13 . Cross- clamp time did not show significant differences showing an average of 72.15 vs 79.86 minutes for Delirium and No delirium patients respectively P: 0.13 .

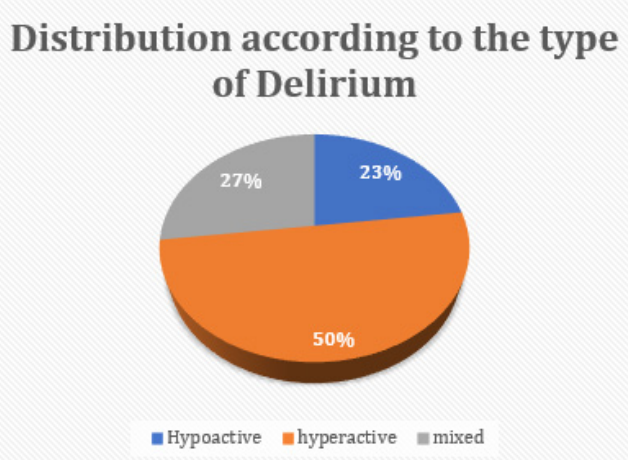

Figure 1: Distribution according to the type of Delirium.

The analysis of postoperative demographic variables did not show significant differences, but they were homogeneous. However, it was observed that the late extubation was developed in 7 patients in the delirium group and in 1of the Non delirium group P: $<0.001$. Thus, 9 in the delirium group (8\%) and 24 in the non-delirium group (21.2\%) P: 0.49 were also found in the variable fever. Atrial fibrillation was present in 11 in the first group (9.7\%) and 19 in the second group (16.8\%) P: 0.038 .
Duration hospitalization stay has been assessed as a complication of Delirium due to in the No delirium group the mean of days was 6.24 and, in the Delirium, group was 11.9 (P: 0.001 ). On the other hand, the duration of Coronary Unit stay was 2.8 days in the group No delirium Vs 7.2 days in the Delirium group (P: 0.001) (Figure 1).

\section{Discussion}

The benefit of MS in comparison to FS has been demonstrated in terms of shorter hospital stay, shorter postoperative ventilation time and reduced transfusion requirements associated with longer CPB and clamping times secondary to technical difficulties due to lower exposure. However, these variables have never been evaluated in the context of a patient with delirium [7].

Cohn and Schmitto have studied and demonstrated the benefits of MICS by valuing different variables such as aesthetic effect, neurological events, bleeding, transfusions and the need for reoperation considering pain, quality of life and recovery to finally assess hospital stay and costs [8].

Tatsuya Yamada et al. assessed the risk of Delirium in MICS vs FS in 2003 [11] Merk et al. demonstrated an increased risk of Delirium in MICS [7]. However, none of the them considered the implication of this in different complications such as hospitalization stay and mortality. Leslie etal. compared surgery vs TAVI in octagenaria demonstrating a higher incidence of Delirium in FS but it did not clarify if they performed MICS previously [12].

In our series, we did not find statistically significant differences in the risk of Delirium in those patients who underwent MS $(12 / 26)$ vs FS (14/26) P: 0. Regarding to age, it had been showed a significant difference in favor of Delirium in patients older than 70 years. That fact has a direct relation with the type of valvular prosthesis used where we see a relationship between Delirium and the biological valves p: 0.02 . The analysis of the postoperative variables showed that those patients with lower postoperative $\mathrm{Hb}$ had more Delirium, however, their direct relationship with MS was not demonstrated, which, despite not having significant results, showed better postoperative $\mathrm{Hb}$ results compared to FS. This is directly related to what Dra. Koster has already demonstrated [13].

The postoperative renal function failure revealed a significant result in favor of Delirium with a P: 0.001 showing no direct relationship with the performance of MS. The analysis of CPB and clamping times did not reveal significant results, however they had a slight tendency to be higher in patients who had Delirium CPB : 100.31 vs 95.15 min. Clamp 79.86 vs 72.15 min respectively P: 0.13 which was also reflected in the analysis of MS Vs FS, CEC: $104.8 \mathrm{~min}$ vs $94.93 \mathrm{~min}$ clamp: $81.35 \mathrm{~min}$ vs $75.68 \mathrm{~min}$ respectively. Thus, patients with late extubation had significant differences in favor of delirium $7(6.2 \%)$ vs $1(9 \%)$ of the nondelirium group. P: 0.001.

We also took into account the complications of Delirium such as the duration of hospitalization stay the inpatient care area 
and coronary unit. Its analysis showed that all the patients who suffered Delirium had statistically significant differences in the days of hospitalization in the inpatient care area and in coronary unit, 11.9 vs 6.24 days and 7.2 vs 2.8 days, respectively (P: 0.001). That result agrees with Dr. Brown et al. publication about Delirium after cardiac surgery [14]. This fact demonstrate that Delirium is a potential complication in patients undergoing postoperative cardiac surgery care not only increasing their morbidity but also increasing greatly health costs as estimated by Gottesman 38 trillion to 152 trillion dollars per year [15].

No mortality events have been registered in any of the groups. Nevertheless, it has been shown a survival improvement survival with MS [7].

Finally, we deduce from the multivariate analysis that the most important risk factors for the development of delirium regardless the approach technique, are age over 70 years with $O R$. $4.98=0.037$ and renal insufficiency with OR. 10.38 P 0.002. This accords with the results obtained by Kurt Bestehorn associating these risk factors. However, we might disagree with the mortality risk duet to it has not been recorded events in our study, which is probably related to the low number of patients we enrolled [16].

This investigation does not find any direct relation between delirium and MS, despite this has been identified in patients older than 70 years regardless of the surgical approach, we believe it is necessary to carry out a prospective study with a larger number of patients such as the one we are currently performing at our center in order to confirm the previous findings and implement a Delirium risk checklist as demonstrated in his paper Koster et al. $[17,18]$.

MS has shown numerous advantages over conventional surgery before this study, nevertheless the risk of Delirium has not been previously assessed in this context. The risk factors and an increasing frequency of Delirium should be taking into account due to its high morbidity rate and significant cost of the health system [7].

Further, investigations comparing MS with last generations valves will be important before determine whether a patient over 70 years can undergo an AVR with MICS.

\section{Acknowledgment}

Prof. Dr. Domingo Balderramo. Statistical Analyst. Hospital Privado Universitario de Córdoba (Institute of Biomedical Sciences of Córdoba) Physician Florence Becerra. Statistical Analyst. University Hospital of Cordoba.

\section{Study Limitations}

The main limitation of our study is being retrospective and belonging to a single center, therefore we tried to analyze a large number of variables. The fact of being unicentric gives the opportunity and concern of future analyzes in a prospective way in order to confirm or refute this theory in a more reliable way.
Although with a low number of patients, this study represents the first analysis of Delirium comparing MICS vs FS.

All patients were retrospectively evaluated by psychiatric specialists. This design of 'patient assessment makes it possible for patients with hypoactive delirium to be obviated or dismissed.

\section{References}

1. Martínez-Velilla N, Alonso Bouzón C, Ripa Zazpe C, Sánchez-Ostiz R (2012) Síndrome confusional agudo postoperatorio en el paciente anciano. Cir Esp 90(2): 75-84.

2. Burns KD, Jenkins W, Yeh D, Procyshyn RM, Schwarz SKW, et al. (2009) Delirium after cardiac surgery: A retrospective case-control study of incidence and risk factors in a Canadian sample. B C Med J 51(5): 206210.

3. Tse L, Schwarz SKW, Bowering JB, Moore RL, Barr AM (2015) Incidence of and Risk Factors for Delirium After Cardiac Surgery at a Quaternary Care Center: A Retrospective Cohort Study. J Cardiothorac Vasc Anesth: 29(6): 1472-1479.

4. Jane S Saczynski, Edward R Marcantonio, Lien Quach, Tamara G Fong, Alden Gross, et al. (2012) Cognitive Trajectories after Postoperative Delirium. N Engl J Med 367: 30-39.

5. Rudolph JL, Inouye SK, Jones RN, Yang FM, Fong TG, et al. (2010) Delirium: An independent predictor of functional decline after cardiac surgery. J Am Geriatr Soc 58(4): 643-649.

6. Koster S, Hensens AG, Schuurmans MJ, Van Der Palen J (2012) Consequences of delirium after cardiac operations. Ann Thorac Surg 93(3): 705-711.

7. Merk DR, Lehmann S, Holzhey DM, Dohmen P, Candolfi P, et al. (2015) Minimal invasive aortic valve replacement surgery is associated with improved survival: a propensity-matched comparisont. Eur J Cardio-Thoracic Surg 47(1): 11-17.

8. Schmitto JD, Mokashi SA, Cohn LH (2010) Minimally Invasive Valve Surgery. JAC 56(6): 455-462.

9. Bakir I, Casselman FP, Wellens F, Jeanmart H, De Geest R, et al. (2006) Minimally Invasive Versus Standard Approach Aortic Valve Replacement: A Study in 506 Patients. Ann Thorac Surg 81(5): 1599-1604.

10. American Psychiatric Association (2013) Diagnostic and Statistical Manual of Mental Disorders.

11. Yamada T, Ochiai R, Takeda J, Shin H, Yozu R (2003) Comparison of early postoperative quality of life in minimally invasive versus conventional valve surgery 17(3): 171-176.

12. Eide LS, Ranhoff AH, Fridlund B, Haaverstad R, Hufthammer KO, et al. (2015) Comparison of Frequency, Risk Factors, and Time Course of Postoperative Delirium in Octogenarians After Transcatheter Aortic Valve Implantation Versus Surgical Aortic Valve Replacement. Am J Cardiol 115(6): 802-809.

13. Koster S, Hensens AG, Schuurmans MJ, van der Palen J (2011) Risk factors of delirium after cardiac surgery: A systematic review. Eur J Cardiovasc Nurs 10(4): 197-204.

14. Brown CH, Laflam A, Max L, Lymar D, Neufeld KJ, et al. (2015) The Impact of Delirium After Cardiac Surgical Procedures on Postoperative Resource Use. Ann Thorac Surg 101(5): 1663-1669.

15. Gottesman RF, Grega MA, Bailey MM, Pham LD, Zeger SL, et al. (2009) Delirium after coronary artery bypass graft surgery and late mortality. Ann Neurol 67(3): 338-344.

16. Bestehorn K, Bestehorn M, Fleck E (2015) Influence of different approaches of aortic valve replacement on the incidence of post-opera- 
tive delirium in intermediate risk patients - a matched pair analysis. Curr Med Res Opin 31(12): 2157-2163.

17. Koster S, Hensens AG, Oosterveld FG, Wijma A, van der Palen J (2009) The Delirium Observation Screening Scale Recognizes Delirium Early after Cardiac Surgery. Eur J Cardiovasc Nurs 8(4): 309-314.

This work is licensed under Creative

Commons Attribution 4.0 License

DOI: 10.19080/JOCCT.2019.14.555879
18. Koster S, Oosterveld FGJ, Hensens AG, Wijma A, van der Palen J (2008) Delirium After Cardiac Surgery and Predictive Validity of a Risk Checklist. Ann Thorac Surg 86(6): 1883-1887.

\begin{tabular}{l} 
Your next submission with Juniper Publishers \\
will reach you the below assets \\
- Quality Editorial service \\
- Swift Peer Review \\
- Reprints availability \\
- E-prints Service \\
- Manuscript Podcast for convenient understanding \\
- Global attainment for your research \\
- Manuscript accessibility in different formats \\
( Pdf, E-pub, Full Text, Audio) \\
- Unceasing customer service \\
Track the below URL for one-step submission \\
https://juniperpublishers.com/online-submission.php \\
\hline
\end{tabular}

